УДК 378:37.03+372.851:0.04.9

Г. Л. Воскобойнікова,

доктор педагогічних наук, професор

(Київський Міжнародний університет)

9 vosk@ukr.net

ORCID: 0000-00003-1483-7496

А. В. Рудик, аспірант

(Київський Міжнародний університет)

balanna@ukr.net

ORCID: 0000-0001-7983-3598

С. О. Воскобойніков,

кандидат педагогічних наук

(Навчально-науковий інститут інформаційної безпеки Національної академії Служби безпеки України, м. Київ)

ORCID: 0000-0002-5863-5880

С. В. Мельник,

кандидат технічних наук, доцент

(Навчально-науковий інститут інформаційної безпеки Національної академії Служби безпеки України, м. Київ)

ORCID: 0000-0002-4231-8469

Д. С. Ступак,

кандидат педагогічних наук

(Житомирський військовий інститут імені С. П. Корольова) dimas1971dukr. net

ORCID: 0000-0001-7638-3982

\title{
ОРГАНІЗАЦІЯ ПІДГОТОВКИ ПЕДАГОГА-ДОСЛІДНИКА НА ОСНОВІ ІНТЕГРОВАНОГО ПОЄДНАННЯ МЕТОДІВ МАТЕМАТИЧНОГО МОДЕЛЮВАННЯ ТА ІНФОРМАЦЙНИХ ТЕХНОЛОГІЙ
}

В статті висвітлено здійснені проектування й розробка та практичне впровадження майстер-класу

"Інтегроване використання математичного моделювання та інформаційних технологій у прикладних галузевих дослідженнях".

Розроблено дизайн платформи віддаленого доступу для дистаниійной форми навчання студентів $в$ умовах магістратури в закладах вищої освіти. Встановлено ефективність практичного впровадження $з$ використанням методу case-study, ситуативного моделювання прикладних задач дослідження у галузі за результатами навчальних досягнень студентів експериментальних груп.

Ключові слова: математичне моделювання, інформаційні технології, прикладні наукові дослідження, дистанційне навчання, платформи віддаленого доступу.

Постановка проблеми. Динамічний розвиток інформаційного суспільства зумовлює прискорений розвиток комп'ютерних та комунікаційних технологій, визначається та характеризується глобальними процесами інформатизації, що, у свою чергу, спричинює модернізацію системи вищої освіти щодо забезпечення доступу до національних i світових інформаційних ресурсів, особливо на етапі магістерської підготовки, в умовах якої формується компетентність педагога-дослідника галузі, відбувається залучення до наукової школи молодих науковців. За таких умов постійно зростають вимоги до підвищення якості вищої освіти. Одним із пріоритетних напрямів модернізації в цій галузі $\epsilon$ впровадження інформаційно-комунікаційних технологій, які забезпечують перебудову навчального процесу у закладах вищої освіти та сприяють підвищенню його ефективності, інтеграції системи вітчизняної освіти до європейського та світового освітнього простору, стимулювання професійного саморозвитку та навчання упродовж життя.

Аналіз останніх досліджень і публікацій. Досягнення цілей сталого розвитку суспільства через науку, технології та інновації потребує створення суспільства освіченого загалу. Наші зусилля спрямовані на започаткування реформи "Нова українська школа", яка є фундаментальною для наступних рівнів освіти, розвитку науки та досліджень та переходу на економіку творчих знань [1].

"Ми хочемо перейти від школи знань до школи, що розвиває компетентності. Україна працює над новою візією науково-дослідницьких пріоритетів (R\&D - priority), які б сприяли сталому розвитку до 2030 року у руслі вирішення завдань відповідно до Резолюції Генеральної Асамблеї ООН "Перетворення нашого світу: Порядок денний в області сталого розвитку на період до 2030 року" (2015 р.). Розвиток 
науки, технологій та інновацій безпосередньо залежить від наявного в країні людського капіталу", переконливо доводить Л. Гріневич [1,2].

Дистанційне навчання відрізняється від інших форм навчання високою інтерактивністю та системою управління пізнавальною діяльністю студентів, передбачає диференціацію та індивідуалізацію навчання. У процесі ДН відбувається поєднання компетентності викладача, інформаційних технологій та мобільності з бажанням і цілеспрямованістю студента.

Платформа дистанційного навчання $є$ центральним елементом дистанційного навчання, програмним забезпеченням для підтримки учасників дистанційного навчання, метою якого є створення та управління педагогічним змістом, залежно від подання інформації, розмежування доступу до неї, ведення обліку існують різноманітні програмні рішення, які відрізняються ступенем складності.

Проблема вибору платформи, на якій буде побудоване віртуальне навчальне середовище $є$ ключовою. Цей вибір залежить від цілого ряду чинників: вимоги до середовища, функціональні характеристики, користувачі середовища, матеріальні ресурси для придбання і підтримки необхідної платформи. На сьогоднішній день у світі існує значне число e-learning платформ для організації електронного навчання, які поділяються на дві великі категорії: 3 закритим кодом (комерційні) та відкритим кодом (поширюються безкоштовно) [3].

Формування дослідницьких вмінь на етапі магістерської підготовки у закладах вищої освіти грунтується, перш за все, на застосуванні універсальних методів дослідження.

Метод математичного моделювання $є$ сучасним потужним пізнавальним методом та ефективним засобом розв'язування прикладних задач. Він грунтується на застосуванні математичної моделі як засобу дослідження реальних об'єктів, процесів чи явищ і полягає у здійсненні певної послідовності етапів. Етапи математичного моделювання за суттю в усіх дослідників схожі й досить широко висвітлені в науковій та навчальній літературі. Для прикладу, В. О. Швець виділяс такі етапи розв'язування прикладної задачі методом математичного моделювання [4]: 1) створення математичної моделі; 2) дослідження математичної моделі - розв'язування отриманої математичної задачі; 3) інтерпретація розв'язків отриманих результатів, тобто переклад розв'язку математичної задачі з мови математики мовою прикладної галузі.

Метод математичного моделювання дозволяє виключити необхідність виготовлення громіздких фізичних моделей, пов'язаних з матеріальними витратами; скоротити час визначення характеристик (особливо при розрахунку математичних моделей 3 використанням комп'ютерних технологій та ефективних обчислювальних методів і алгоритмів).

Мета: проектування освітнього процесу на основі інтегрованого поєднання методів математичного моделювання та інформаційних технологій.

Відповідно до мети визначено завдання дослідження:

1) здійснити проектування та розробку майстер-класу;

2) розробити дизайн платформи віддаленого доступу для дистанційної форми навчання студентів в умовах магістратури в закладах вищої освіти.

Методи дослідження: системний аналіз наукових джерел та практичного використання методів математичного моделювання, проектування, математичне моделювання, статистичні методи, метод casestudy моніторингу навчальних досягнень студентів після проходження майстер-класу.

Виклад основного матеріалу дослідження. Для практичного використання математичного моделювання доцільно застосовувати прийнятні класифікації математичних моделей за цілями моделювання: дескриптивні, оптимізаційні та управлінські моделі. За методами реалізації та оператором: аналітичні, алгоритмічні, лінійні, нелінійні. Також прийнятною є класифікація за параметрами. В загальному випадку параметри, які описують стан і поведінку об'єкта моделювання можна розділити на такі множини: 1) сукупність вхідних (керованих) впливів на об’єкт; 2) сукупність впливу зовнішнього середовища (некерованих); 3) сукупність вихідних характеристик. Залежно від виду використаних множин параметри моделі можуть поділятися на: якісні і кількісні; дискретні і неперервні; змішані.

При побудові моделей часто приходиться стикатися з недоліком інформації. При цьому можливі такі варіанти опису невизначеності параметрів:

- детерміноване - значення всіх параметрів моделі визначається детермінованими величинами (тобто кожному параметру відповідає конкретне число або функція), спосіб відповідає повній визначеності параметрів;

- стохастичне - значення всіх або окремих параметрів моделі визначаються випадковими величинами, заданими щільностями ймовірностями;

- випадкове - значення всіх або окремих параметрів моделі встановлюються випадковими величинами, заданими оцінками щільностей ймовірностей, отриманими в результаті обробки обмеженої експериментальною вибіркою даних параметрів; 
- інтервальне - значення всіх або окремих параметрів моделі описують інтервальними величинами, заданими інтервалом, утвореним мінімальним і максимально можливими значеннями параметра;

- нечітке - значення всіх або окремих параметрів моделі описуються функціями належності відповідній множині.

Статистичні моделі будуються на припущенні про те, що модельований процес є випадковим i досліджується статистичними методами, зокрема методами Монте-Карло [5].

Одним із методів дослідження слабо структурованих систем є розроблений Т. Сааті [6] метод аналізу ієрархій, який дозволяє звести дослідження навіть дуже складних систем до послідовності парних порівнянь відповідним чином визначених компонент. Метод аналізу $\epsilon$ замкнутою логічною конструкцією, що забезпечує за допомогою простих правил аналіз складних проблем у всій їх різноманітності.

Сучасні методики дисциплін природничо-наукового циклу поетапно здійснюють представлення природничо-наукових явищ у вигляді образної, символьної, звукової інформації, які відображають одну й ту ж сутність даного явища, що дозволяє певним чином кодувати різнорідну інформацію, надавати їй чітке словесне формулювання, математичне обгрунтування, експериментальне підтвердження, що принагідно відображає зміст методу моделювання у процесі навчання математики. Математичне моделювання є окремою міжпредметною галуззю знань, через використання якого розкривається єдність оточуючого світу і методу моделювання як методу пізнання [7].

Однією з основних особливостей імітаційного моделювання за методом Монте-Карло є використання спеціальних комп'ютерних програм. Це відбувається тому, що на п’ятому етапі генерування випадкових сценаріїв реалізації проекту повторюються 500-1000 разів. Метод Монте-Карло - це чисельний метод, основу якого становить одержання великого числа реалізацій випадкового процесу, який формується так, щоб імовірнісні характеристики (математичні очікування, імовірність деяких подій, імовірність попадання траєкторії процесу в деяку область) дорівнювали певним величинам задачі, яка розв'язується [8].

Було встановлено [9], що ідеї усереднення присутні у багатьох чисельних методах. Зокрема розрахункова формула, такого популярного методу, як метод скінченних різниць (МСР) представляє собою середнє арифметичне у випадку квадратної сітки, середнє зважене у випадку прямокутної сітки та адаптованого шаблону. Метод скінченних елементів (МСЕ) також використовує усереднення при побудові інтерполяційного поліному на окремому елементі. В схемах випадкових блукань методу Монте-Карло теж використовується зважене усереднення. Це дає можливість для створення нових моделей і методів.

Детерміновані моделі передбачають жорсткі функціональні зв’язки між змінними моделі, а стохастичні - припускають наявність випадкових впливів на досліджувані показники [10].

Для формування компетентності педагога-дослідника у процесі магістерської підготовки в закладах вищої освіти розроблено майстер-клас "Інтегроване використання математичного моделювання та інформаційних технологій у прикладних галузевих дослідженнях" (iз застосуванням методик використання математичного моделювання, науковий доробок "Методики використання математичного моделювання у прикладних галузевих дослідженнях для формування професійної готовності майбутніх магістрів математики до технологізації освітнього процесу у профільній школі" Рудик А., 2018 р.).

Дизайн платформи віддаленого доступу для дистанційної участі у проведенні майстер-класу інтегрованого використання математичного моделювання та інформаційних технологій у прикладних галузевих дослідженнях розроблено авторами 3 урахуванням специфіки прикладних галузевих досліджень та структуровано відповідні тематичні розділи.

Авторський програмний продукт, складова дизайну платформи (Authoring Packages) включає електронний навчально-методичний комплекс "Інтегроване використання математичного моделювання та інформаційних технологій у прикладних галузевих дослідженнях", кейси ситуативних задач для використання математичного моделювання розроблені на основі застосування технологій і програмного забезпечення HTML, PowerPoint, Trainer Soft, Macromedia Authorware, 3dmax та ін.

Управління віртуальним навчальним середовищем платформи здійснюється через системи Learning Management Systems (LMS) i Learning Content Management Systems.

Для моніторингу навчальних досягнень студентів дистанційної форми навчання після дистанційного проведення майстер-класу "Інтегроване використання математичного моделювання та інформаційних технологій у прикладних галузевих дослідженнях" у процесі вивчення навчальної дисципліни "Методологія та організація наукових досліджень з основами інтелектуальної власності" (в умовах упровадження елементів дуальної освіти та застосування індивідуального графіку навчання магістрів) використано метод case-study, ситуативного моделювання прикладних задач дослідження у галузі відповідно тем розділів майстер-класу та вибору студентами експериментальних груп факультетів фізико-математичного та інформаційних технологій (спеціалізація "Управління інноваційною 
діяльністю") алгоритмів їх вирішення, проектування дизайну експерименту із застосуванням методу математичного моделювання, використання методик математичного моделювання при обчисленні прогнозованих ризиків, застосуванні ризик-менеджменту реалізації проектів управлінських рішень, а також навчання методів математичного моделювання в умовах технологізації освітніх процесів у профільних школах.

Для порівняння результативності навчання студентів експериментальних груп (загальною кількістю 100 респондентів) проведено тестування 3 навчальної дисципліни "Методологія та організація наукових досліджень з основами інтелектуальної власності" студентів контрольних груп (загальною кількістю 100 респондентів), які навчалися за затвердженими програмами (рис.1).
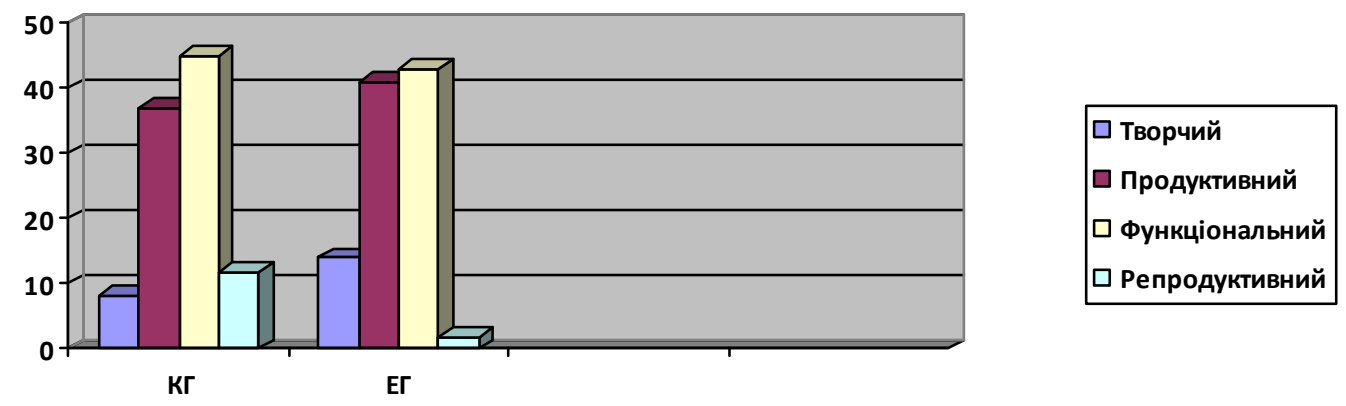

Рис.1. Діаграма порівняння результативності експериментального навчання студентів експериментальних і контрольних груп з навчальної дисципліни "Методологія та організація наукових досліджень з основами інтелектуальної власності" з використанням методу case-study, ситуативного моделювання прикладних задач дослідження у галузі

В експериментальних групах студентів, після дистанційного проведення майстер класу навчальні досягнення покращились, відповідно: творчий рівень - 14; продуктивний -41 ; функціональний -43 ; репродуктивний рівень застосування методів математичного моделювання у прикладних дослідженнях галузі виявлено тільки у 2 студентів.

Висновки. На основі проведеного системного аналізу наукових джерел та практичного використання методів математичного моделювання здійснено проектування й розробку та практичне впровадження майстер-класу "Інтегроване використання математичного моделювання та інформаційних технологій у прикладних галузевих дослідженнях".

Розроблено дизайн платформи віддаленого доступу для дистанційної форми навчання студентів в умовах магістратури в закладах вищої освіти. Встановлено ефективність практичного впровадження 3 використанням методу case-study, ситуативного моделювання прикладних задач дослідження у галузі за результатами навчальних досягнень студентів експериментальних груп.

\section{СПИСОК ВИКОРИСТАНИХ ДЖЕРЕЛ ТА ЛІТЕРАТУРИ}

1. Матеріали Міністерського круглого столу щодо розвитку S\&T у межах 15-го STS форуму, 7 жовтня 2018, м. Кіото (Японія). Виступ Л. Гріневич [Електронний ресурс]. - Режим доступу: https: //mon.gov.ua/ua/news/ukrayina-pracyuye-nad-novoyu-viziyeyu-naukovo-doslidnickih-prioritetiv-rd-priority-yaki-bspriyali-dosyagnennyu-cilej-stalogo-rozvitku-do-2030-roku-liliya-grinevich (дата звернення: 7.10.2018р.).

2. Transforming Our World : the 2030 Agenda for Sustainable Development), прийнятий 25 вересня 2015 року [Електронний ресурс]. - Режим доступу : https://www.millennium-institute.org/ (дата звернення: 7.10.2018 p.).

3. Організація дистанційного навчання. Створення електронних навчальних курсів та електронних тестів : [навчальний посібник] / В. В. Вишнівський, М. П. Гніденко, Г. І. Гайдур, О. О. Ільїн. - Київ : ДУТ, 2014. $140 \mathrm{c}$.

4. Швець В. О. Математичне моделювання як змістова лінія шкільного курсу математики / В. О. Швець // Дидактика математики : проблеми і дослідження [міжнародний збірник наукових робіт]. - Донецьк : Вид-во ДонНУ. - 2009. - № 32. - С. 16-23.

5. Ульянченко О. В. Дослідження операцій в економіці. / О. В. Ульянченко. - Харків : Гриф, 2002. - 580 с.

6. Саати Т. Л. Принятие решений. Метод анализа иерархий / Т. Л. Саати. - М. : Радио и связь, 1993. -320 с

7. Пинский А. А. Математическая модель в системе межпредметных связей / А. А. Пинский // Межпредметные связи естественно математических дисциплин : [сборник статей]. - М., 1980. - С. 108-119.

8. Корнило I. М. Прогнозування показників організаційно-економічних процесів за допомогою математичних моделей / І. Корнило // Журнал Науковий огляд. - 2015. - № 8 (18). - С. 1-6.

9. Хомченко А.Н. В. Две модели усреднения граничных потенциалов на адаптируемом шаблоне / А. Н. Хомченко, М. Т. Наджафов, Н. В. Валько // Геометричне та комп’ютерне моделювання. - Харків: Харк. держ. університет харчування та торгівлі. - 2004. - № 8. - С. 26-31. 
10. Економетрія : [навчальний посібник для студ. вищ. навч. закл] / О. Л. Лещинський, В. В. Рязанцева, О. О. Юнькова. - К. : МАУП, 2003. - 208 с.

\section{REFERENCES (TRANSLATED \& TRANSLITERATED)}

1. Materialy Ministers'koho kruhloho stolu shchodo rozvytku S\&T u mezhakh 15-ho STS forumu, 7 zhovtnia 2018, m. Kioto (Iaponiia). Vystup L. Hrinevych [Materials of the Ministerial Round Table on S \& T Development within the 15th STS Forum, October 7, 2018, Kyoto, Japan. Speech by L. Grinevich] [Electronic resource]. - Access mode : https: //mon.gov.ua/ua/news/ukrayina-pracyuye-nad-novoyu-viziyeyu-naukovo-doslidnickih-prioritetiv-rd-priorityyaki-b-spriyali-dosyagnennyu-cilej-stalogo-rozvitku-do-2030-roku-liliya-grinevich (Data zvernennia : 7.10.2018).

2. Transforming Our World : the 2030 Agenda for Sustainable Development) [Elektronnyi resurs]. - Rezhym dostupu : https://www.millennium-institute.org/ (Data zvernennia : 7.10 .2018 r.).

3. Orhanizatsiia dystantsiinoho navchannia. Stvorennia elektronnykh navchal'nykh kursiv ta elektronnykh testiv [Organization of Distance Learning. Creating E-Learning Courses and Electronic Tests] : [navchal'nyi posibnuk] / V. V. Vishnevsky, M. P. Gnidenko, G. I. Gaidur, O. O. Ilyin - Kyiv : DUT, 2014. - 140 s.

4. Shvets V. O. Matematychne modeliuvannia yak zmistova liniia shkil'noho kursu matematyky [Mathematical Modeling as a Content Line of the School Course of Mathematics] / V. O. Shvets // Dydaktyka matematyky : problemy i doslidzhennia [Didactics of Mathematics : Problems and Research] : [mizhnarodnyi zbirnyk naukovykh robit]. - Donets'k: Publishing House DonNU. - 2009. - No. 32. - P. 16-23.

5. Ulyanchenko O. V. Investigation of operations in the economy / O. V. Ulyanchenko. - Kharkiv : Grif, 2002. $580 \mathrm{p}$.

6. Saati T. L. Pryniatie reshenii. Metod analiza yerarkhii [Decision-Making. Method of Analysis of Hierarchies] / T. L. Saati. - Moscow : Radio and Communications, 1993. - $320 \mathrm{p}$

7. Pinsky A. A. Matematicheskaia model' v sisteme mezhpredmetnykh sviazei [Mathematical Model in the System of Intersubject Connections] / A. A. Pinsky // Mezhpredmetnyie sviazi estestvenno matematicheskikh dystsyplin [Intersubject Communications of Natural Mathematical Disciplines] : [sbornik statei]. - M., 1980. - P. 108-119.

8. Kornilo I. M. Forecasting of Indicators of Organizational and Economic Processes with the Help of Mathematical Models / I. Kornilo / Journal of Scientific Review. - 2015. - No. 8 (18). - P. 1-6.

9. Khomchenko A. N. Dve modeli usredneniia hranychnykh potentsialov na adaptiruemom shablone [Two Models of Averaging of Boundary Potentials on an Adaptable Template] / A. N. Khomchenko, M. T. Najafov, N. V. Valko // Heometrychne ta kompiuterne modeliuvannia [Geometrical and Computer Modeling]. - Kharkiv : Kharkov. State University of Food and Commerce. - 2004. - No. 8. - P. 26-31.

10. Ekonometriia [Econometrics]: [navchalnyi posibnik dlia stud. vysch. navch. zakl] / O. L. Leshchinsky, V. V. Riazantsev, O. O. Yunkov. - K. : MAUP, 2003. - 208 p.

\section{Воскобойникова Г. Л., Рудык А. В., Воскобойников С. В., Мельник С. В., Ступак Д. Е. Организация подготовки педагога-исследователя, на основе интегрированного сочетания методов математического моделирования и информационных технологий.}

В статье освещены проектирование и разработка и практическое внедрение мастер-класса "Интегрированное использование математического моделирования и информационных технологий в прикладных отраслевых исследованиях".

На основе проведенного системного анализа научных и практических методов математического моделирования и разработки проектов в области инженерных и прикладных наук обосновано содержание теоретической части мастер-класса.

Разработан дизайн платформы отдаленного доступа для дистанционной формь обучения студентов 8 условиях магистратуры в учреждениях высшего образования. Авторский программный продукт, включает электронный учебно-методический комплекс "Интегрированное использование математического моделирования и информационных технологий в прикладных отраслевых исследованиях", кейсы ситуативных задач разработанные на основе технологий и программного обеспечения HTML, PowerPoint, Trainer Soft, Macromedia Authorware, 3dmax.

Подтверждена эффективность практического внедрения с использованием метода case-study, ситуационного моделирования прикладных задач исследования в области по результатам учебных достижений студентов экспериментальных групп.

Ключевые слова: математическое моделирование, информационные технологии, прикладные научные исследования, дистанционное обучение, платформы отдаленного доступа.

\section{Voskoboinikova G. L., Rudyk A. V., Voskoboinikov S. V., Melnik S. V., Stupak D. E. Organization of Training of a Teacher-Researcher, Based on an Integrated Combination of Methods of Mathematical Modeling and Information Technologies.}

The article highlights the design and development and practical implementation of the master class "Integrated use of mathematical modeling and information technology in applied industry research." 
Based on the conducted system analysis of scientific and practical methods of mathematical modeling and development of projects in the field of engineering and applied sciences, the content of the theoretical part of the master class is substantiated.

The design of a remote access platform for distance learning of students in the magistracy in higher education institutions has been developed.

The design of the remote access platform for remote participation in conducting the master class of integrated use of mathematical modeling and information technologies in applied branch research has been developed taking into account the specifics of applied branch research.

The author's software product includes an electronic educational and methodical complex "Integrated use of mathematical modeling and information technologies in applied industry research", case studies of cases developed on the basis of technologies and software HTML, PowerPoint, Trainer Soft, Macromedia Authorware, 3 dmax.

The method of case-study, situational modeling of applied research problems in the industry, in accordance with the topics of the master-class sections and the choice students of the experimental groups of algorithms for their solution was used to monitor the students' learning achievements in the distance learning form.

The effectiveness of practical implementation using the case-study method, situational modeling of applied research problems in the field according to the results of educational achievements of students of experimental groups was confirmed.

Key words: mathematical modeling, information technologies, applied scientific researches, distance learning, remote access platforms. 